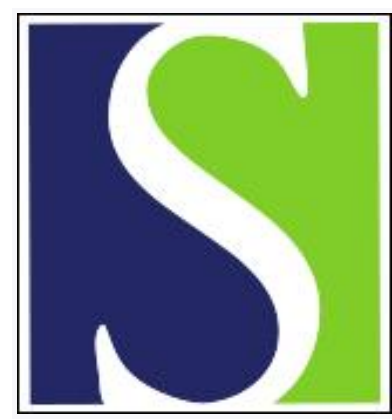

Scand J Work Environ Health 2012;38(4):380-390

https://doi.org/10.5271/sjweh.3282

Published online: 20 Feb 2012, Issue date: 01 Jul 2012

Work at night and breast cancer - report on evidence-based options for preventive actions

by Bonde JP, Hansen J, Kolstad HA, Mikkelsen S, Olsen JH, Blask DE, Härmä M, Kjuus H, de Koning HJ, Olsen J, Møller M, Schernhammer ES, Stevens RG, Åkerstedt T

Affiliation: Department of Occupational and Environmental Medicine, Bispebjerg University Hospital, Bispebjerg Bakke 23, DK-2400 Copenhagen NV, Denmark. jbon0004@bbh.regionh.dk

The following articles refer to this text: $2012 ; 38(4): 291-297$;

2013;39(2):170-177; 2013;39(4):425-426; 2014;40(3):295-304;

2020;46(4):446-453; 2020;46(6):557-569

Key terms: breast cancer; cancer; circadian rhythm; evidence-based option; melatonin; night work; occupational disease; prevention; shift work

This article in PubMed: www.ncbi.nlm.nih.gov/pubmed/22349009 


\title{
Work at night and breast cancer - report on evidence-based options for preventive actions
}

\author{
by Jens Peter Bonde, MD, DMSc, ${ }^{1}$ Johnni Hansen, MSc, PhD, ${ }^{2}$ Henrik A Kolstad, MD, PhD, ${ }^{3}$ Sigurd \\ Mikkelsen, MD, DMSc, ${ }^{1}$ Jergen H Olsen, MD, DMSc, ${ }^{2}$ David E Blask, MD, PhD, ${ }^{4}$ Mikko Härmä, MD, PhD, ${ }^{5}$ \\ Helge Kjuus, MD, PhD, ${ }^{6}$ Harry J de Koning, MD, PhD, ${ }^{7}$ Jørn Olsen, MD, PhD, , , 9 Morten Møller, MD, \\ DMSC, ${ }^{10}$ Eva S Schernhammer, MD, DrPH, ${ }^{11}$ Richard G Stevens, MD, PhD, ${ }^{12},{ }^{13}$ Thorbjörn Åkerstedt, PhD ${ }^{14}$
}

\begin{abstract}
Bonde JP, Hansen J, Kolstad HA, Mikkelsen S, Olsen JH, Blask DE, Härmä M, Kjuus H, de Koning HJ, Olsen J, Møller M, Schernhammer ES, Stevens RG, Åkerstedt T. Work at night and breast cancer: Report on evidence-based options for preventive actions. Scand J Work Environ Health. 2012;38(4):380-390. doi:10.5271/sjweh.3282
\end{abstract}

\begin{abstract}
In 2007, the International Agency for Research on Cancer classified shift work involving circadian disruption as probably carcinogenic to humans (group 2A), primarily based on experimental and epidemiologic evidence for breast cancer. In order to examine options for evidence-based preventive actions, 16 researchers in basic, epidemiological and applied sciences convened at a workshop in Copenhagen 26-27 October 2011. This paper summarizes the evidence from epidemiological and experimental studies and presents possible recommendations for prevention of the effects of night work on breast cancer.

Among those studies that quantified duration of shift work, there were statistically significant elevations in risk only after about 20 years working night shift. It is unclear from these studies whether or not there is a modest but real elevated risk for shorter durations. Hence, restriction of the total number of years working night shift could be one future preventive recommendation for shift workers. The diurnal secretion of melatonin by the pineal gland with peak in secretory activity during the night is a good biochemical marker of the circadian rhythm. Disruption of the diurnal melatonin secretion pattern can be diminished by restricting the number of consecutive night shifts. Reddish light and reduced light intensity during work at night could potentially help diminish the inhibitory activity of light with strong intensity on the melatonin secretion, but further mechanistic insight is needed before definite recommendations can be made. Earlier or more intensive mammography screening among female night shift worker is not recommended because the harm-benefit ratio in this age group may not be beneficial. Preventive effects of melatonin supplementation on breast cancer risk have not been clearly documented, but may be a promising avenue if a lack of side effects can be shown even after long-term ingestion. Women with previous or current breast cancer should be advised not to work night shifts because of strong experimental evidence demonstrating accelerated tumor growth by suppression of melatonin secretion.

Work during the night is widespread worldwide. To provide additional evidence-based recommendations on prevention of diseases related to night shift work, large studies on the impact of various shift schedules and type of light on circadian rhythms need to be conducted in real work environments.
\end{abstract}

Key terms circadian rhythm; melatonin; occupational disease; night work; prevention; shift work.

1 Department of Occupational and Environmental Medicine, Bispebjerg Hospital, University of Copenhagen, Denmark.

2 Institute of Cancer Epidemiology, Danish Cancer Society, Copenhagen, Denmark.

3 Danish Ramazzini Centre, Department of Occupational Medicine, Aarhus University Hospital, Aarhus, Denmark.

4 Department of Structural \& Cellular Biology, School of Medicine, Tulane University, New Orleans, Louisiana, USA.

5 Centre of Expertise on Human Factors at Work, Finnish Institute of Occupational Health, Helsinki, Finland.

6 Department of Occupational Medicine and Epidemiology, National Institute of Occupational Health, Oslo, Norway.

7 Department of Public Health, Erasmus MC, University Medical Center Rotterdam, Rotterdam, The Netherlands.

8 Department of Epidemiology, University of California, Los Angeles, USA

9 Aarhus Universitet, Institut for Epidemiologi og Socialmedicin, University of Aarhus, Aarhus, Denmark.

10 Department of Neuroscience and Pharmacology, University of Copenhagen, Copenhagen, Denmark.

11 Channing Laboratory, Department of Medicine, Brigham and Women's Hospital and Harvard Medical School, Boston, MA, USA.

12 Department of Epidemiology, Harvard School of Public Health, Boston, MA, USA.

13 Division of Epidemiology \& Biostatistics, Department of Community and Health Care, University of Connecticut Health Center, Farmington, USA.

${ }^{14}$ Institute for Stress Research, Stockholm University and Karolinska Institutet, Stockholm, Sweden.

Correspondence to: Jens Peter Bonde, Department of Occupational and Environmental Medicine, Bispebjerg University Hospital, Bispebjerg Bakke 23, DK-2400 Copenhagen NV, Denmark. [E-mail: jpb@bbh.regionh.dk] 
About $15-20 \%$ of employees in Europe and USA work night shifts and an increasing segment of the working population in industrialized countries worldwide work non-day shifts (1). In 2007, the International Agency for Research on Cancer (IARC) classified shift work that involves circadian disruption as "probably carcinogenic to humans" (group 2A) $(2,3)$. This conclusion was based on (i) sufficient evidence in animal studies for carcinogenicity of light during the daily dark period, (ii) strong experimental data suggestive of a causal link between circadian disruption and development of malignant tumors and (iii) limited epidemiological evidence of increased risk of breast cancer among women working night shifts.

In Denmark, exposures classified by the IARC as carcinogenic to humans (group 1) or probably carcinogenic to humans (group 2A) are considered for inclusion in the list of occupational diseases. Between 2007 and 2011, the Danish National Board of Occupational Injuries recognized some 110 cases of breast cancer as diseases caused by work at night and therefore eligible for compensation. Assuming that work at night indeed contributes to the occurrence of human breast cancer and considering the high prevalence of night work, it has become an important priority to examine if current knowledge allows for evidence-based recommendations of preventive actions. For this purpose, 16 researchers in biological, epidemiological and applied sciences convened at a workshop in Copenhagen, 26-27 October 2011. This report provides a brief account of background information, conclusions and recommendations that emerged from the workshop. While increasing evidence on shift work and cancer risk prompted the workshop, it is acknowledged that preventive measures should also accommodate other known and suspected health risks related to shift work such as sleep disorders, accidents, cardiovascular disease, and metabolic disorders (4). This paper, however, deals with breast cancer only.

\section{Light, circadian rhythms, and melatonin}

Circadian rhythms are evident in virtually all living animals and plants. They are genetically encoded and adjusted to local time primarily by an entrainment to the daily photoperiod via light reaching the eye. Circadian rhythms (including, for example, sleep/wake cycles, body temperature, blood pressure, hormone secretion, digestion, metabolism, and cell turnover) are pivotal for survival and driven and maintained in a hierarchical manner by a central pacemaker (the biologic master clock) located in the suprachiasmatic nucleus ( $\mathrm{SCN}$ ) of the hypothalamus. The SCN also orchestrates the independent peripheral clocks in the rest of the organism into a coherent time organization with optimal time structure and biological function for the entire body (5). The endogenous clockwork is entrained to the ambient diurnal light/dark cycle given by the rotation of the earth in relation to the sun, primarily through photosensitive retinal ganglion cells containing the newly detected photopigment melanopsin (peak sensitive to blue light of 460-484 $\mathrm{nm}$ ). It transmits time of day, duration of the day, and day of year information to the pineal gland by the SCN and the sympathetic nerve system (6). From the pineal gland, the time information is signaled to organs and tissues by secretion of the neurohormone melatonin - a lipophilic indole - and binding to cell membrane-bound melatonin receptors. Melatonin is produced during the biological night (from dusk to dawn), whereas the daytime production is virtually zero. While the peak of the melatonin secretion signals time relative to the astronomical 24-hour light/dark cycle, the duration of the melatonin surge indicates the length of the day, and indirectly the time of the year (season). Exposure to light during night immediately reduces melatonin production dependent of light intensity, wavelength and duration of exposure, and may in addition cause desynchronization of the master clock from the peripheral clocks, including the fine-tuned circadian gene expression in local tissues and cells (7-9). During the last decades, melatonin receptors have been shown to be present in several peripheral tissues outside the brain and also in neoplasms of the mammary gland.

In the scientific literature, the term "circadian disruption" is defined as desynchronization of internal circadian rhythms relative to ambient dark/light cycle, including desynchronization of the SCN with peripheral clocks. Circadian disruption is partly but not fully characterized by change in physiological markers of the circadian rhythm such as amplitude, duration, and timing of melatonin secretion. In a broader sense, circadian disruption describes objective or subjective proxies of changed circadian rhythm (such as sleep disturbance and tiredness). In this paper, the term is used in the broader meaning, unless otherwise specified, recognizing that little is known about the relation between real life shift work and physiological markers of circadian rhythm.

The vast majority of experimental evidence supports the hypothesis that under the conditions of complete darkness, high circulating levels of melatonin during the night not only provide a potent circadian anti-cancer signal to established cancer cells but also help to protect normal cells from the initiation of the carcinogenic process in the first place $(7,8)$. Most of the earlier studies using experimental models of either spontaneous or chemically induced rodent models of mammary carcinogenesis demonstrate an accelerated development of mammary tumors in response to exposure to constant bright fluorescent light at night. More recent experimental work demonstrates that chronically advancing the phasing of light exposure (chronic jet 
lag) plays a significant role in malignant progression in tumor-bearing mice (10). Thus a change of the timing of the light/dark cycle by steady phase advances in light exposure may represent a potentially important biological mechanism for increased cancer growth.

Studies of female rats bearing human breast cancer xenografts show that growth and metabolic activity of tumors increase significantly as the intensity of light exposure increases, and that these effects are caused by a corresponding suppression of nocturnal melatonin secretion. Moreover, mechanistic evidence indicates that the ability of the nocturnal melatonin to suppress tumor fatty acid uptake and metabolism, particularly linoleic acid, is compromised by circadian disruption (8). This experimental evidence provides a link between exposure of healthy human female subjects to light at night and enhancement of human breast oncogenesis via suppression of the nocturnal melatonin anti-cancer signal. The suppression of melatonin production by exposure to light at night, leading to augmented tumor growth and linoleic uptake/metabolism deserves serious consideration as a potential biological mechanism to explain the association between breast cancer and night shift work.

Melatonin is the most stable and reliable biological marker of circadian rhythm in humans and therefore information on how shift systems and light exposure affects melatonin homeostasis is important when considering options for preventive actions (11). Four out of five prospective cohort studies among women without night work have shown increased risk of breast cancer related to low urine levels of the melatonin metabolite, 6-sulfatoxymelatonin in morning spot samples or 24 hour samples (12-16). Unfortunately there are only few studies that in some detail outline the melatonin exposure profile (peak, amplitude, duration, timing) among people working night shifts (17-20) except among nurses working in fastforward-rotating shifts (21). These studies report a small reduction (typically less than 20\%) in melatonin secretion and a flattened secretion profile among night compared to day workers. Changes seemed more pronounced among permanent night workers but were also found for other shift workers after the night shift (18). Although light with wavelength $460-480 \mathrm{~nm}$ creates the strongest suppression of melatonin (22), even dim red light causes suppression; work in constant dim red light is hardly a realistic option since most work tasks require better lighting conditions for safety and productivity reasons.

\section{The IARC evaluation in 2007}

The IARC evaluation included three cohort studies (two of them prospective) and five case-control studies addressing the risk of breast cancer in relation to various definitions of non-day work, including evening, night, and early morning shifts as defined by self-reports or estimated from job exposure matrices (23-30). Six of the eight studies showed increased relative risk in the range of 1.4-2.2 when extreme categories of non-day work were compared (23-28). Data on the overall relative risk for breast cancer according to uniform definitions of night shift work cannot be directly obtained from the studies. Moreover, eight of nine cohort studies of flight attendants - who may be exposed to both jetlag, cosmic radiation, and shift work - reported increased risk of breast cancer (3). Other studies addressing risk of breast cancer in occupations with a high prevalence of night work were not included in the IARC evaluation. All three studies of nurses reported significantly increased risk for breast cancer for night shift work beyond 20-30 years in the range of 1.4-2.2 (24-26).

\section{Update of the epidemiologic evidence}

Since the IARC evaluation, four additional observational studies have been published, three of which were case-control studies (31-33) and one cohort study (34). In general these studies tended to cover more details concerning shift systems (eg, rotating versus permanent shift and number of consecutive shifts) compared to the older studies, which in particular focused on duration. Two case-control studies nested within cohorts of nurses indicate an association between night shift work and breast cancer after adjustment for most known potential confounders $(32,33)$. In the Lie et al study (32), an increased risk is observed among nurses with $\geq 5$ consecutive night shifts during $\geq 5$ years, while in the Hansen \& Stevens study (33) an increased risk is observed even after a short duration of night shift work. The two other studies indicated no overall effect of night shift work $(31,34)$, but the Pesch et al study (31) reported a non-significantly increased risk with cumulative number of night shifts. None of the studies had sufficient power to stratify on different histologic subtypes of breast cancer or age of onset for breast cancer (eg, pre-, postmenopausal cancer). Only one of the four studies adjusted for participation in breast cancer screening activities. Uncontrolled confounding by screening could potentially contribute to underestimation of risk of breast cancer if screening is less frequent among night workers, which is indicated by some data (31). This is because screening not only detects cancer at an earlier stage but also breast cancers that would not progress to clinical detection. An overview of breast cancer risk according to non-day shift work is provided in table 1 based upon the 12 epidemiological studies included in this report. 
A main limitation of epidemiological studies so far is uncertainty in how best to define work schedules and crude quantification of work at night across studies. Thus, exposure misclassification in studies using exposure matrices may diminish exposure contrasts, thereby reducing the ability to identify effects whereas recall bias in the case-control studies may generate a spurious association or overestimate a true risk. Further limitations are uncertain exposure-response relationships and findings restricted to few specific occupations (ie, nursing) in 5 out of 12 studies.

\section{How to prevent circadian disruption?}

Disruption of the circadian rhythm is assumed to be a main pathway from shift work to disease, although other mechanisms may also be involved (35). This applies not only to risk of cancer but also to other known and suspected shift-work-related disorders (1). Complete elimination of work at night is not foreseeable in either low- or high-income countries. Therefore it is important to identify and implement shift systems that minimize circadian disruption and other factors that might be involved in carcinogenicity such as behavioral and lifestyle factors.

The degree of circadian adjustment varies significantly in relation to shift schedules, although the evidence is still limited (36-39). Factors influencing the degree of circadian disruption are mostly related to specific shift characteristics like timing, speed (ie, number of consecutive night shifts), duration and direction of shift rotation as well as factors related to the actual light exposure (intensity, wavelength and timing). On the other hand, also individual factors (eg, diurnal preference and sleep pattern) and other environmental factors (eg, eating and lighting when not at work) influence the circadian adjustment.

\section{Cumulative number of years working nightshifts}

Setting limits to the total lifelong "work at night" dose in analogy with guidelines on cumulative radiation dose would be justified if reliable knowledge on cancer risk in relation to cumulative night work exposure were available. For those studies that quantified duration, statistically significant increases in risk were only seen for $\geq 20$ years; but it is unclear from the existing studies whether or not there is risk for shorter durations (table 1). Overall there is no clear pattern of increased risk with increasing number of years working at night. Moreover, a threshold value separating risk and no-risk cannot currently be identified.

\section{Cumulative number of night shifts}

Night shift work per se is not expected to be a risk factor of breast cancer but is an upstream cause for light-at-night exposure, melatonin suppression, circadian phase shift, and sleep deprivation, which may be more proximal determinants of breast cancer. In any case, one would expect that breast cancer risk increases as the cumulative number of nightshifts increase (40, 41). Since the cumulative number of night shifts was analyzed using different metrics in the six epidemiological studies addressing this issue $(27,28,31-34)$, the consistency of results cannot be evaluated without access to raw data.

\section{Number of consecutive night shifts}

An alternative strategy to diminish circadian disruption is to minimize the number of consecutive nightshifts in order to prevent circadian adjustment and maximize recovery to the normal day-oriented sleep/wake rhythm. Even rapidly rotating shifts may cause sleep deprivation and should therefore be organized with between-shift periods of sufficient duration to allow for full recovery in terms of rest and sleep (42). Based on most studies and recommendations, the use of forward-rotating shift systems (1-2 consecutive night shifts) seems to be more favorable for sleep, performance, and the social life of the workers than the use of more slowly rotating shift rotations (3-5 consecutive nightshifts) $(4,36,37,42)$. Rapidly forward-rotating shift systems also suit older workers better because of their shortened day sleep after a night shift and hence decreased adjustment to consecutive night shifts $(42,43)$.

Epidemiologic evidence indicating that working slowly rotating shift systems (working consecutively $4-5$ or more nights) is related to a higher risk of breast cancer has only been reported in one study (32) and indirectly in another study reporting the highest breast cancer risk among nurses with periods of both permanent night shifts and rotating shifts compared to nurses with rotating shifts only (33).

\section{Number of nightshifts per month}

One early study (31) showed an increased risk of breast cancer with increasing average number of night shifts per month but two later studies did not $(32,34)$.

\section{Working permanent night shifts}

Since most permanent night shift workers return to a normal diurnal rhythm during days off, they are not expected to have a risk for breast cancer that differs from workers on rotating night shift work beyond the 
potential effect of number of shifts. However, little is known about differences between specific night shift schedules in relation to the cumulated melatonin excretion, eg, if permanent night shift differs from slow- or fast-rotating shifts with respect to cumulated melatonin secretion over a longer time period with the same number of night shifts. So far, only one study has reported risk for breast cancer for permanent and rotating nightshifts separately (33). In remote work sites, it may be feasible to combine permanent nightshifts with a switch of the day/night rhythm during days off work and thus achieve circadian readjustment over extended periods of time. Detailed measures of melatonin across different work shift periods in longitudinal cohorts are warranted.

\section{Intensity of light at night}

Experimental studies show that white light provides a strong signal to the brain centre regulating the circadian rhythm and produces the most pronounced suppression of melatonin secretion from the pineal gland (the maximum effect in the blue end of the spectrum, ie, at wave length $460-480 \mathrm{~nm})(44,45)$. Thus, exposure to bright white light during night shifts may be used to stimulate adaptation to night work, if desirable (46) (eg, for permanent night workers), but bright white light should be avoided if such adaptation is not desirable (eg, in fastrotation shifts where dim red light is preferable when possible and safe considering the work tasks). Similarly, permanent night shift workers should avoid bright light after work (eg, by using dark sun-glasses) and return home to sleep, while fast-rotating shift workers should be exposed to the morning bright light in order not to change the normal circadian rhythm. Bright light exposure during the first half of the biological night (before the melatonin peak) will delay the circadian rhythm, and bright light exposure during the latter half, after the melatonin peak, will advance the rhythm (47). The effects of implementation of light exposure regimens to delay or advance the circadian rhythm may therefore be unpredictable at the individual level, depending on their circadian phase when they are exposed to light. Large intervention studies are needed before specific light exposure regimens are recommended for night shifts in different types of shifts.

\section{Nutritional issues}

Dietary factors may influence cancer growth and metabolism (48). Experimental evidence indicates that melatonin partly exerts its anti-proliferative effects by inhibiting uptake of linoleic acid (an essential omega-6 polyunsatturated acid) into the cells (8). There is, however, no human evidence to indicate ameliorating effects of specific diets during night work relative to cancer or other disease risks. Recommendations for a healthy diet to the general population also apply for night shift workers until good research indicates otherwise.

\section{Rest and short sleep periods during night shifts}

It is well established that shift work at night is related to poor sleep quality and shorter sleep duration (49), and the latter has been associated with increased risk for breast cancer (50). Periods of rest and "power naps" during night shifts can increase alertness but there is no evidence that power naps reduce circadian disruption or prevent breast cancer.

\section{Vulnerability in shift work}

There is no available data on vulnerability to cancer among shift workers but several studies have examined individual factors related to outcomes such as being able to cope with shift work, fatigue, and sleepiness (51). Factors like aging and being predisposed to an earlier circadian phase ("morningness") decrease the speed of adaptation to consecutive night shifts. Eveningness compared to morningness seems to facilitate permanent night work, but not rotating shift work. Shift workers who are transferred to day work become more morning types. During the last few years, there has been some focus on the shift work disorder: sleep or alertness problems supposedly characterizing individuals working at night but the prevalence of these disorders among day workers is unknown.

Research into clock genes and other genes of importance for circadian rhythm is at an early stage (52) and so far there is no reliable genetic test that can identify persons who are more sensitive to circadian disruption than others. In general, primary or secondary preventive action independent of individual genetic disposition is recommended since the working environment should be organized to suit all workers.

\section{Mammography screening}

Breast cancer screening is offered to the female population in the age range 50-74 years in many countries regardless of risk status. Extending breast cancer screening to pre-menopausal women working night shifts has been considered. However, the harm-benefit ratio is higher among women $<50$ years unless a very strong risk factor (eg, first line family occurrence) is present. Considering the magnitude of risk related to work at night (if any, a relative risk $\leq 2$ ), it is not justified to recommend 
Table 1. Shift-work and breast cancer risk studies in chronology order by duration and cumulative number of nights. [ND=not determined; $\mathrm{RR}=$ relative risk; $95 \% \mathrm{Cl}=95 \%$ confidence interval; $\mathrm{P}$-value=test for trend]

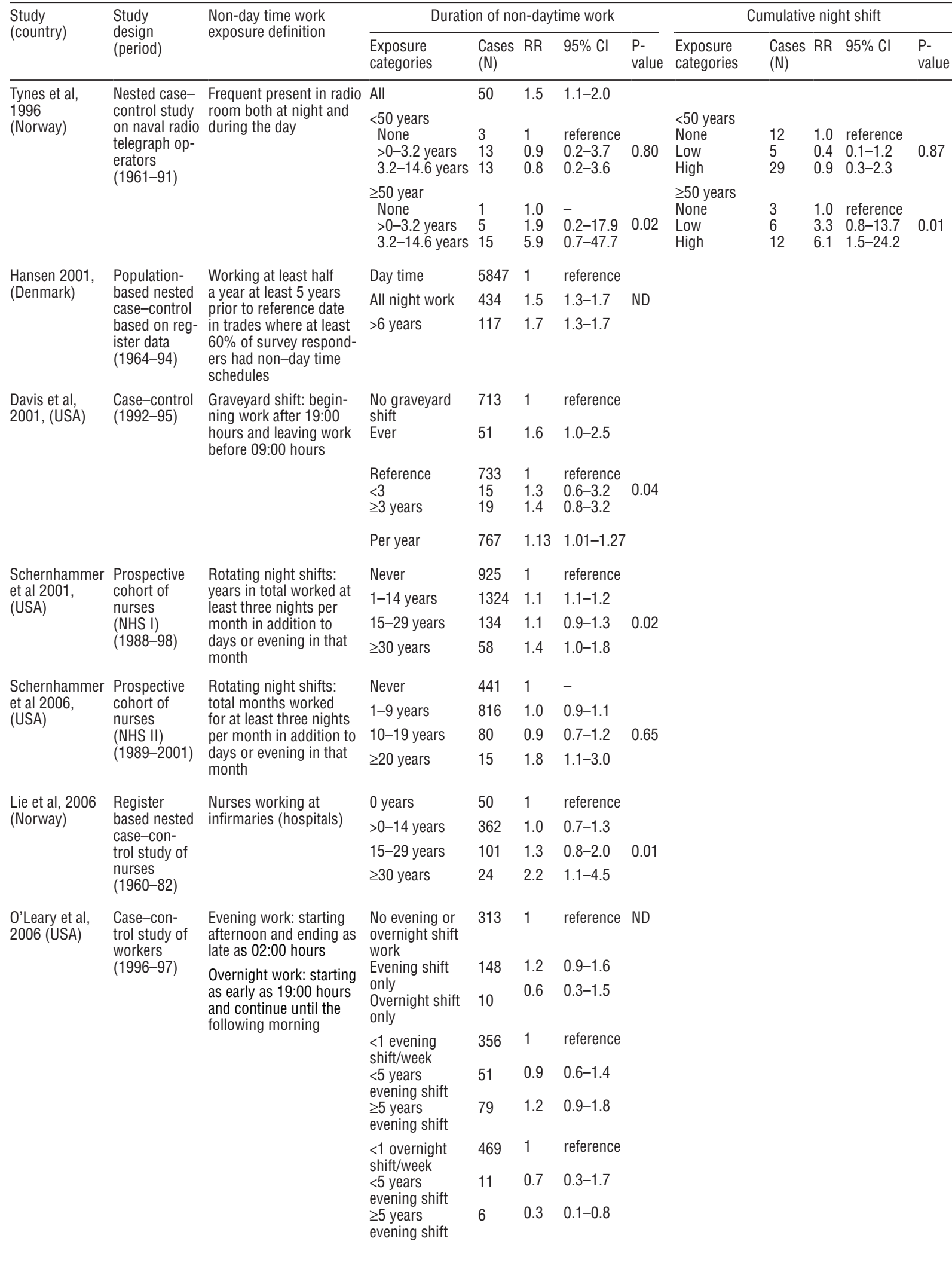


Table 1. Continued

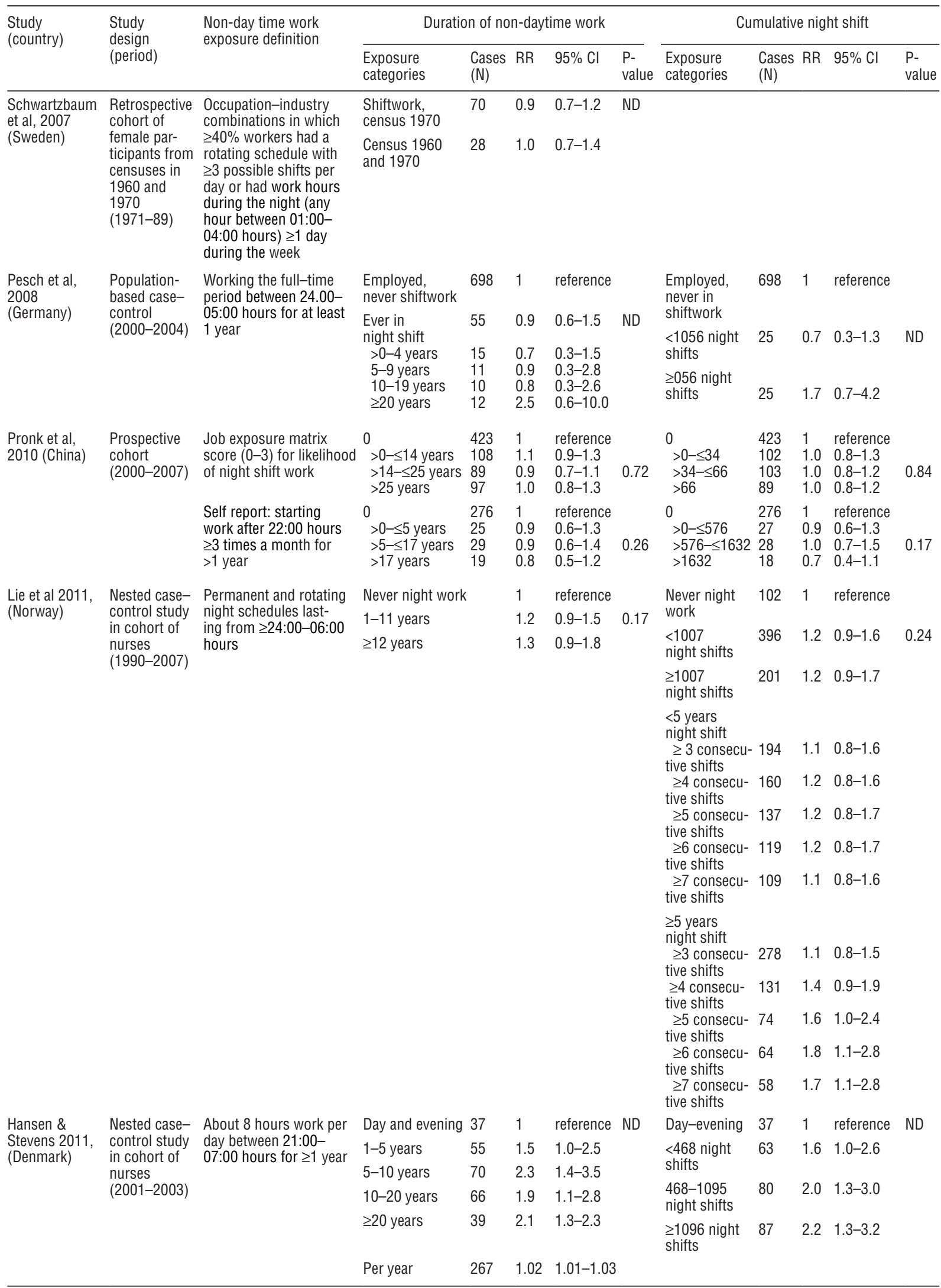


earlier or more intensive mammography screening to female night shift workers by means of present screening technology. The relatively higher harm-benefit ratio in younger women is the result of lower incidence of breast cancer, more false positive tests, and over diagnosing. Any risk due to ionizing radiation conferred by the screening procedure is marginal (53).

\section{Periodic health examinations}

Benefits of periodic health examinations of night shift workers are not documented in the scientific literature (54). Periodic health examinations without defined and documented content may cause inappropriate health concern, increased burden on the healthcare system, and inappropriate use of resources $(55,56)$. The workshop acknowledges that there is a need for counseling of night shift workers regarding more general preventive lifestyle changes, but benefits from general health examinations are disputed.

\section{Treatment with melatonin}

From a theoretical point of view, the oncostatic effect of melatonin might be due to different mechanisms: (i) a direct binding of melatonin to the receptors in the tumor tissue, or (ii) an indirect effect via an entrainment of the circadian clock in the SCN or a peripheral clock located in the tumor tissue itself (57). For the direct effect, a constant saturation of the receptor during both day and night would be optimal. Contrarily, to phase-change the central or peripheral clock, a single physiological melatonin dose should be given at a critical certain circadian time point, where the phase response of the circadian clock is maximal. Clinical treatments of cancer, including breast cancer, with large doses of melatonin given at bedtime, have been reported (58), but the value of such a treatment needs empirical support. Melatonin, taken orally, might or might not in the future be useful in the prevention of breast cancer among shift workers, and randomized controlled trials documenting beneficial effects on the circadian rhythm are warranted. Both long-term side effect as well as dose and circadian time point for the medication have to be determined. Investigations of neurotransmitters and receptors in the optic system transmitting light information to pineal gland might result in more effective future drugs than melatonin to restore normal circadian rhythms among shift workers.

\section{Is breast cancer an occupational disease?}

The legal definition of an occupational disease and the criteria for recognition and worker compensation varies profoundly between countries. Arguments in favor of recognizing breast cancer as an occupational disease include (i) an increasing number of epidemiologic studies reporting an association between breast cancer and shift work (including nightwork), and (ii) plausible mechanisms linking work at night and breast cancer related to the disruption of circadian rhythms. Arguments against recognition raise the following shortcomings (i) weak associations limited to selected occupational groups, (ii) the poor definition of the nature of shift work, and (ii) unclear exposure-response relationships (59). The current scientific evidence, together with the large differences both in causal requirements and compensation systems between countries, does not allow for a global scientifically based recommendation to include (or not include) breast cancer in national lists of occupational diseases for compensation purposes. However, the scientific evidence of a potentially causal association between night work and breast cancer and the vast documentation of other detrimental health effects from shift work clearly calls for primary prevention, including a limitation of night work.

\section{Concluding remarks and recommendations}

Four epidemiologic studies published between 2008 and 2011 provide no reason to revise the IARC's conclusion that shift work involving circadian disruption is probably carcinogenic to humans

In experimental animals, exposure to light during the biological night is strongly linked to an excess risk of tumors. This happens through a biological mechanism that may also operate in humans. In absence of sufficient human data, it is therefore prudent to regard night shift work that includes circadian disruption as carcinogenic.

Epidemiologic studies provide no clear pattern of increased risk with increasing number of years working at night, but studies that quantified the duration of shift work observed elevations in risk only after about 20 years. Restriction of total number of night shifts or number of years working night shift may be considered, although current limited scientific evidence does not allow for more specific recommendations.

\section{Options to limit circadian disruption}

- Rapidly rotating shifts (1-2 consecutive nights) cause less disruption of circadian rhythms than slowly rotating shifts ( $\geq 3$ consecutive shifts); 
- Delay of circadian phase causes less circadian disruption than advance of circadian phase and for this reason forward- rather than backward-rotating shifts are recommended;

- Permanent night work is an uncommon solution to avoid circadian disruption and is feasible in remote worksites where a night-oriented rhythm during days off is possible;

- Modified light intensity during work at night such as working in bright white light to increase adoption or in dim red light to prevent adoption may prove feasible methods to minimize circadian disruption, but further research on different light regimens is needed. This also includes studies addressing the optimal trade-off between effects on circadian rhythms and alertness;

- Considering the magnitude of increased risk related to work at night (if any) and because the harm-benefit ratio is unknown, it is at present not justified to offer earlier or more intensive mammography screening to female night shift workers;

- Melatonin supplementation might in the future be useful in the prevention of breast cancer among shift workers, but randomized controlled trials documenting effects on the circadian rhythm and long-term side effects are needed before this is recommended. Both dose and circadian time point for the medication has to be determined;

- Current evidence does not allow a scientifically based recommendation to include (or exclude) breast cancer in national lists of occupational diseases for compensation purposes;

- Women with breast cancer should be advised not to work night shifts because of the strong experimental evidence demonstrating that suppression of melatonin secretion causes augmented tumor growth; and

- The vast documentation of other detrimental health effects from shift work clearly calls for primary prevention including the limitation of night work.

In conclusion, the IARC classification calls for specific preventive actions. Considering the uncertainties in the scientific evidence, specific recommendations to regulate for example the number of years working night shifts, the number of consecutive nightshifts, or the specific spacing and number of night shifts in forwardrotating shift work cannot be scientifically justified from the current knowledge. Decisions on specific preventive measures should be revised as new evidence becomes available.

\section{Research needs}

Work during the night is widespread and growing in developing countries. Therefore, understanding the specific risks associated with night work and their biological mechanisms of action are needed in order to minimize such risks on a scientific basis. Recently a working group identified several major domains of nonday shifts and shift schedules that should be captured in future studies (shift system, duration working nonday shifts, and shift intensity) (38). In order to provide more specific and evidence-based recommendations on the prevention of disease related to work at night, more research needs to be conducted on the impact of various shift schedules and the type of light and other exposures on melatonin and the circadian rhythms of workers in real-work environments (38). There is some evidence that long-term shift work leads to promoter methylation changes in specific circadian genes as well as whole genome wide alterations (60), and studies on epigenetic changes induced by shift work along the life course are needed.

\section{Acknowledgement}

The Danish Society of Cancer, Danish regions, and the Danish Nurses' Organization sponsored the workshop. Secretary Hanne Tulinius is thanked for organizing the meeting.

\section{References}

1. Rajaratnam SM, Arendt J. Health in a 24-h society. Lancet. 2001;358(9286):999-1005. http://dx.doi.org/10.1016/S01406736(01)06108-6.

2. Straif K, Baan R, Grosse Y, Secretan B, El GF, Bouvard V, Altieri A, Benbrahim-Tallaa L, Cogliano V. Carcinogenicity of shift-work, painting, and fire-fighting. Lancet Oncol. 2007;8(12):1065-6. http://dx.doi.org/10.1016/S14702045(07)70373-X.

3. International Agency for research on Cancer. Painting, firefighting and shift work. Lyon: IARC; 2010. p. 9-764.

4. Härmä M. Workhours in relation to work stress, recovery and health. Scand.J Work Environ.Health. 2006;32(6):502-14. http://dx.doi.org/10.5271/sjweh.1055.

5. Arendt J. Melatonin and human rhythms. Chronobiol Int. 2006;23(1-2):21-37. http://dx.doi. org/10.1080/07420520500464361.

6. Moller M, Baeres FM. The anatomy and innervation of the mammalian pineal gland. Cell Tissue Res. 2002;309(1):139 50. http://dx.doi.org/10.1007/s00441-002-0580-5. 
7. Blask DE. Melatonin, sleep disturbance and cancer risk. Sleep Med Rev. 2009;13(4):257-64. http://dx.doi.org/10.1016/j. smrv.2008.07.007.

8. Blask DE, Hill SM, Dauchy RT, Xiang S, Yuan L, Duplessis T, Mao L, Dauchy E, Sauer LA. Circadian regulation of molecular, dietary, and metabolic signaling mechanisms of human breast cancer growth by the nocturnal melatonin signal and the consequences of its disruption by light at night. J Pineal Res. 2011;51(3):259-69. http://dx.doi.org/10.1111/j.1600079X.2011.00888.x.

9. Arendt J, Skene DJ. Melatonin as a chronobiotic. Sleep Med Rev. 2005;9(1):25-39. http://dx.doi.org/10.1016/j. smrv.2004.05.002.

10. Filipski E, Delaunay F, King VM, Wu MW, Claustrat B, Grechez-Cassiau A, et al. Effects of chronic jet lag on tumor progression in mice. Cancer Res. 2004;64(21):7879-85. http:// dx.doi.org/10.1158/0008-5472.CAN-04-0674.

11. Mirick DK, Davis S. Melatonin as a biomarker of circadian dysregulation. Cancer Epidemiol.Biomarkers Prev. 2008;17(12):3306-13. http://dx.doi.org/10.1158/1055-9965. EPI-08-0605.

12. Schernhammer ES, Hankinson SE. Urinary melatonin levels and breast cancer risk. J Natl Cancer Inst. 2005;97(14):1084-7. http://dx.doi.org/10.1093/jnci/dji190.

13. Schernhammer ES, Berrino F, Krogh V, Secreto G, Micheli A, Venturelli E, et al. Urinary 6-sulfatoxymelatonin levels and risk of breast cancer in postmenopausal women. J NatlCancer Inst. 2008;100(12):898-905. http://dx.doi.org/10.1093/jnci/djn171.

14. Schernhammer ES, Hankinson SE. Urinary melatonin levels and postmenopausal breast cancer risk in the Nurses" Health Study cohort. Cancer Epidemiol Biomarkers Prev. 2009;18(1):74-9. http://dx.doi.org/10.1158/1055-9965.EPI08-0637.

15. Schernhammer ES, Berrino F, Krogh V, Secreto G, Micheli A, Venturelli E, et al. Urinary 6-Sulphatoxymelatonin levels and risk of breast cancer in premenopausal women: the ORDET cohort. Cancer Epidemiol Biomarkers Prev. 2010;19(3):72937. http://dx.doi.org/10.1158/1055-9965.EPI-09-1229.

16. Travis RC, Allen DS, Fentiman IS, Key TJ. Melatonin and breast cancer: a prospective study. J Natl Cancer Inst. 2004;96(6):475-82. http://dx.doi.org/10.1093/jnci/djh077.

17. Marie HA, Helene GA, Hansen J. Diurnal urinary 6-sulfatoxymelatonin levels among healthy Danish nurses during work and leisure time. Chronobiol Int. 2006;23(6):120315. http://dx.doi.org/10.1080/07420520601100955.

18. Burch JB, Yost MG, Johnson W, Allen E. Melatonin, sleep, and shift work adaptation. J Occup Environ Med. 2005;47(9):893-901. http://dx.doi.org/10.1097/01. jom.0000177336.21147.9f.

19. Gibbs M, Hampton S, Morgan L, Arendt J. Predicting circadian response to abrupt phase shift: 6-sulphatoxymelatonin rhythms in rotating shift workers offshore. J Biol Rhythms. 2007;22(4):368-70. http://dx.doi. org/10.1177/0748730407302843.

20. Grundy A, Sanchez M, Richardson H, Tranmer J, Borugian
M, Graham CH, Aronson KJ. Light intensity exposure, sleep duration, physical activity, and biomarkers of melatonin among rotating shift nurses. Chronobiol Int. 2009;26(7):144361. http://dx.doi.org/10.3109/07420520903399987.

21. Grundy A, Tranmer J, Richardson H, Graham $\mathrm{CH}$, Aronson KJ. The Influence of Light at Night Exposure on Melatonin Levels among Canadian Rotating Shift Nurses. Cancer Epidemiol Biomarkers Prev. 2011;20(11):2404-12. http:// dx.doi.org/10.1158/1055-9965.EPI-11-0427.

22. Gooley JJ, Rajaratnam SM, Brainard GC, Kronauer RE, Czeisler CA, Lockley SW. Spectral responses of the human circadian system depend on the irradiance and duration of exposure to light. Sci Transl Med. 2010;2(31):31-3.

23. Hansen J. Increased breast cancer risk among women who work predominantly at night. Epidemiology. 2001;12(1):74-7. http://dx.doi.org/10.1097/00001648-200101000-00013.

24. Lie JA, Roessink J, Kjaerheim K. Breast cancer and night work among Norwegian nurses. Cancer Causes Control. 2006;17(1):39-44. http://dx.doi.org/10.1007/s10552-005$3639-2$.

25. Schernhammer ES, Kroenke CH, Laden F, Hankinson SE. Night work and risk of breastcancer. Epidemiology. 2006;17(1):108-11. http://dx.doi.org/10.1097/01.ede.0000190539.03500.c1.

26. Schernhammer ES, Laden F, Speizer FE, Willett WC, Hunter DJ, Kawachi I, Colditz GA. Rotating night shifts and risk of breast cancer in women participating in the nurses' health study. J Natl Cancer Inst. 2001;93(20):1563-8. http://dx.doi. org/10.1093/jnci/93.20.1563.

27. Tynes T, Hannevik M, Andersen A, Vistnes AI, Haldorsen T. Incidence of breast cancer in Norwegian female radio and telegraph operators. Cancer Causes Control. 1996;7(2):197204. http://dx.doi.org/10.1007/BF00051295.

28. Davis S, Mirick DK, Stevens RG. Night shift work, light at night, andrisk of breastcancer. JNatlCancer Inst. 2001;93(20):1557-62. http://dx.doi.org/10.1093/jnci/93.20.1557.

29. O'Leary ES, Schoenfeld ER, Stevens RG, Kabat GC, Henderson K, Grimson R, et al. Shift work, light at night, and breast cancer on Long Island, New York. Am J Epidemiol. 2006;164(4):358-66. http://dx.doi.org/10.1093/aje/kwj211.

30. Schwartzbaum J, Ahlbom A, Feychting M. Cohort study of cancer risk among male and female shift workers. Scand J Work Environ Health. 2007;33(5):336-43. http://dx.doi.org/10.5271/sjweh.1150.

31. Pesch B, Harth V, Rabstein S, Baisch C, Schiffermann M, Pallapies D, et al. Night work and breast cancer - results from the German GENICA study. Scand J Work Environ Health.2010;36(2):134-41. http://dx.doi.org/10.5271/ sjweh.2890.

32. Lie JA, Kjuus H, Zienolddiny S, Haugen A, Stevens RG, Kjaerheim K. Night work and breast cancer risk among Norwegian nurses: assessment by different exposure metrics. Am J Epidemiol. 2011;173(11):1272-9. http://dx.doi. org/10.1093/aje/kwr014.

33. Hansen J, Stevens RG. Case-control study of shift-work and breast cancer risk in Danish nurses: Impact of shift systems. 
Eur J Cancer. 2011.

34. Pronk A, Ji BT, Shu XO, Xue S, Yang G, Li HL, et al. Night-shift work and breast cancer risk in a cohort of Chinese women. Am J Epidemiol. 2010;171(9):953-9. http://dx.doi.org/10.1093/aje/kwq029.

35. Fritschi L, Glass DC, Heyworth JS, Aronson K, Girschik $\mathrm{J}$, Boyle $\mathrm{T}$, et al. Hypotheses for mechanisms linking shift work and cancer. Med Hypotheses. 2011;77(3):430-6. http://dx.doi.org/10.1016/j.mehy.2011.06.002.

36. Driscoll TR, Grunstein RR, Rogers NL. A systematic review of the neurobehavioural and physiological effects of shift work systems. Sleep Med Rev. 2007;11(3):179-94. http://dx.doi.org/10.1016/j.smrv.2006.11.001.

37. Sallinen M, Kecklund G. Shift work, sleep, and sleepiness - differences between shift schedules and systems. Scand J Work Environ Health. 2010;36(2):121-33. http://dx.doi.org/10.5271/sjweh.2900.

38. Stevens RG, Hansen J, Costa G, Haus E, Kauppinen T, Aronson KJ, et al. Considerations of circadian impact for defining 'shift work' in cancer studies: IARC Working Group Report. Occup Environ Med. 2011;68(2):154-62.

39. Haus E, Smolensky M. Biological clocks and shift work: circadian dysregulation and potential long-term effects. Cancer Causes Control. 2006;17(4):489-500. http://dx.doi.org/10.1007/s10552-005-9015-4.

40. Stevens RG, Blask DE, Brainard GC, Hansen J, Lockley SW, Provencio I, et al. Meeting report: the role of environmental lighting and circadian disruption in cancer and other diseases. Environ Health Perspect. 2007;115(9):1357-62. http://dx.doi. org/10.1289/ehp.10200.

41. Erren TC, Pape HG, Piekarski C, Reiter RJ. Not all shifts are equal: it's time for comprehensive exposure metrics in chronodisruption research. Cancer Res. 2008;68(10):4011. http://dx.doi.org/10.1158/0008-5472.CAN-08-0279.

42. Härmä M, Hakola T, Kandolin I, Sallinen M, Vahtera J, Anne B, Mutanen P. A controlled intervention study on the effects of a very rapidly forward rotating shift system on sleepwakefulness and well-being among young and elderly shift workers. Int J Psychophysiol. 2006;59(1):70-9. http://dx.doi. org/10.1016/j.ijpsycho.2005.08.005.

43. HärmäMI,Hakola T, Åkerstedt T, Laitinen JT.Age andadjustment to night work. Occup Environ Med. 1994;51(8):568-73. http://dx.doi.org/10.1136/oem.51.8.568.

44. Brainard GC, Hanifin JP, Greeson JM, Byrne B, Glickman G, Gerner E, Rollag MD. Action spectrum for melatonin regulation in humans: evidence for a novel circadian photoreceptor. J Neurosci. 2001;21(16):6405-12.

45. Thapan K, Arendt J, Skene DJ. An action spectrum for melatonin suppression: evidence for a novel non-rod, non-cone photoreceptor system in humans. J Physiol. 2001;535(Pt 1):2617. http://dx.doi.org/10.1111/j.1469-7793.2001.t01-1-00261.x.

46. Lowden A, Åkerstedt T, Wibom R. Suppression of sleepiness and melatonin by bright light exposure during breaks in night work. J Sleep Res.2004;13(1):37-43. http://dx.doi.org/10.1046/j.1365-2869.2003.00381.x.
47. Khalsa SB, Jewett ME, Cajochen C, Czeisler CA. A phase response curve to single bright light pulses in human subjects. J Physiol. 2003;549:945-52. http://dx.doi.org/10.1113/jphysiol.2003.040477.

48. Sauer LA, Blask DE, Dauchy RT. Dietary factors and growth and metabolism in experimental tumors. J Nutr Biochem. 2007;18(10):637-49. http://dx.doi.org/10.1016/j.jnutbio.2006.12.009.

49. Garde AH, Hansen AM, Hansen J. Sleep length and quality, sleepiness and urinary melatonin among healthy Danish nurses with shift work during work and leisure time. Int Arch Occup Environ Health. 2009;82(10):1219-28. http://dx.doi. org/10.1007/s00420-009-0419-4.

50. Kakizaki M, Kuriyama S, Sone T, Ohmori-Matsuda K, Hozawa A, Nakaya N, et al. Sleep duration and the risk of breast cancer: the Ohsaki Cohort Study. Br J Cancer. 2008;99(9):1502-5. http://dx.doi.org/10.1038/sj.bjc.6604684.

51. Saksvik IB, Bjorvatn B, Hetland H, Sandal GM, Pallesen $\mathrm{S}$. Individual differences in tolerance to shift work--a systematic review. Sleep Med Rev. 2011;15(4):221-35. http://dx.doi.org/10.1016/j.smrv.2010.07.002.

52. Stevens RG. Circadian disruption and breast cancer: from melatonin to clock genes. Epidemiology. 2005;16(2):254-8. http://dx.doi.org/10.1097/01.ede.0000152525.21924.54.

53. De Gelder R, Draisma G, Heijnsdijk EA, de Koning HJ. Population-based mammography screening below age 50: balancing radiation-induced vs prevented breast cancer deaths. Br J Cancer. 2011;104(7):1214-20. http://dx.doi.org/10.1038/ bjc.2011.67.

54. Bonde JP, Andersen JH, Frost P, Kaergaard A, Kolstad HA, Thulstrup AM. [Health examinations in connection with night work]. Ugeskr.Laeger. 2007;169(21):2005-7.

55. Boulware LE, Barnes GJ, Wilson RF, Phillips K, Maynor K, Hwang C, et al. Value of the periodic health evaluation. Evid Rep Technol Assess.(Full.Rep.). 2006;(136):1-134.

56. Marshall KG. Prevention. How much harm? How much benefit? 3. Physical, psychological and social harm. CMAJ. 1996;155(2):169-76.

57. Sahar S, Sassone-Corsi P. Circadian clock and breast cancer: a molecular link. Cell Cycle. 2007;6(11):1329-31. http://dx.doi. org/10.4161/cc.6.11.4295.

58. Lissoni P. Is there a role for melatonin in supportive care? Support Care Cancer. 2002;10(2):110-6. http://dx.doi. org/10.1007/s005200100281.

59. Breast cancer on the night shift. Lancet. 2009;373(9669):1054. http://dx.doi.org/10.1016/S0140-6736(09)60626-7.

60. Zhu Y, Stevens RG, Hoffman AE, Tjonneland A, Vogel UB, Zheng T, Hansen J. Epigenetic impact of long-term shift work: pilot evidence from circadian genes and whole-genome methylation analysis. Chronobiol Int. 2011;28(10):852-61. http://dx.doi.org/10.3109/07420528.2011.618896.

Received for publication: 9 January 2012 